\title{
Research on Reform Innovation and Entrepreneurship Education in Colleges and Universities
}

\author{
Bin Wang \\ Xi’an International University, Xi’an, Shaanxi, 710077
}

Keywords: reform; innovation and entrepreneurship education

\begin{abstract}
The "weakness" of the support system for college students' innovation and entrepreneurship and the "deviation" of the entrepreneurial evaluation mechanism scientifically examine these realistic dilemmas, which is helpful to advocate the idea of infiltrating the concept of innovation and entrepreneurship education in the basic education system, actively cultivate the innovation and entrepreneurship culture in colleges and universities, explore the path of innovation and entrepreneurship, and improve the innovation and entrepreneurship education system in colleges and universities, accelerate the cultivation of high-quality innovative talents, and promote students' high-quality employment and entrepreneurship.
\end{abstract}

\section{Introduction}

At present, China's economic development has entered a new normal, the total employment pressure still exists, and the employment situation of college graduates is still grim. Under the background of mass entrepreneurship and innovation, innovation and entrepreneurship education has important practical significance for improving the quality of university personnel training and the quality of graduate employment. In 2015, the General Office of the State Council issued the "Implementation Opinions on Deepening the Reform of Innovation and Entrepreneurship Education in Colleges", clearly requiring deepening the reform of innovation and entrepreneurship education in colleges, cultivating high-quality innovative talents, promoting the all-round development of students, and promoting students' high-quality employment and entrepreneurship.

\section{The Status Quo of Innovation and Entrepreneurship Education in Colleges and Universities}

Innovation is the soul of social progress, and entrepreneurship is an important way to promote economic and social development and improve people's livelihood. Colleges have gathered many outstanding intellectual youths and shouldered the heavy responsibility of cultivating innovative talents, which is undoubtedly the main body of college students' innovation and entrepreneurship education. The number of papers and technological innovation projects of various types of science and technology and philosophy in China has doubled every year, but it can only be a large number of innovative countries. It is still not a quality innovation power. China's innovation and entrepreneurship education started late, and domestic colleges initiated innovation and entrepreneurship education at the end of the 20th century. In 1998, Tsinghua University hosted the first Tsinghua University Entrepreneurship Competition, becoming the first university in China to introduce the College Student Entrepreneurship Competition to Asia. In 2002, the Ministry of Education identified nine institutions, including Tsinghua University, Renmin University of China, and Beijing University of Aeronautics and Astronautics, as pilot institutions for entrepreneurship education, which marked the official launch of entrepreneurship education in China. For more than ten years, some localities and universities have continuously innovated talent training models, carried out and implemented innovation and entrepreneurship education, and conducted useful explorations on the theory and practice of innovation and entrepreneurship education in colleges. Emerging design competitions, college students' employment and entrepreneurship guidance courses, and college students have emerged. A variety of innovative entrepreneurship education forms such as the Pioneer Park (base), the theory and practice of innovation and entrepreneurship 
education have achieved fruitful results. At the same time, we must also be soberly aware that many colleges still pay insufficient attention to innovation and entrepreneurship education in their ideological concepts. There is a lag in the concept of education, a serious disconnection between the curriculum system and practice, a weak sense of innovation and entrepreneurship of teachers, and a lack of guidance. The outstanding methods of teaching methods, lack of entrepreneurial practice platforms, etc., the effect of innovation and entrepreneurship education is not ideal.

\section{The Realistic Dilemma in the Reform of Innovation and Entrepreneurship Education}

At present, the top-level design of innovation and entrepreneurship education in colleges has been released, which not only spurs the assembly number of improving the quality of innovation and entrepreneurship education, but also depicts the blueprint for the reform of innovation and entrepreneurship education in colleges in the future. However, looking at the current situation of innovation and entrepreneurship education in colleges, the reform of innovation and entrepreneurship education in colleges still faces many difficulties and problems, which restricts the reform and development of innovation and entrepreneurship education in colleges to varying degrees.

Promoting student development is the value pursuit and responsibility of education. However, in the actual educational life, the children in the basic education stage do not enjoy the educational experience that should belong to them. In fact, every student has a huge potential for innovation. However, under the guidance of the test mode and the value-based theory, the endless sea of questions and endless examinations are the life course of the children. At the same time, the curriculum is not highly diversified, the homework is demanding standard answers, the students' hands-on practice opportunities are less, the children's desire for innovation is restrained, the creativity is lacking, and the creative potential is ruthlessly "castrated", causing the children not to innovate or not. Dare to innovate, not to innovate, not to innovate.

In the basic education stage, the students' physical and mental development is in an immature period. The dominant position of the teachers is often above the subjective status of the students. The teachers become absolutely unquestionable authority. The field space arrangement of the school classrooms presents the centrality of teachers' power. Some personal thoughts and "deviant" ideas that emerged during the education and life process will be denied and banned as long as they do not meet the teacher's educational concept. The students' creative enthusiasm is consumed and destroyed countless times. Over time, the students will not dare Suspicion of authority, no question, no bold imagination, no risk-taking, and thus gradually lack of criticism and negative thinking, the nature of innovation and consciousness have gradually entered the "hibernation period."

In 2013, the total number of students enrolled in various higher education schools nationwide reached 34.6 million, and the gross enrollment rate of higher education reached $34.5 \%$. China's higher education has entered the stage of popularization. However, most college students' perceptions of university functions still remain at the level of university's changing destiny and the university's cultivation of elites. The deviation from the university's understanding makes the college students' awareness of ivory towers and entrepreneurship very weak. At the same time, in addition to the regular employment and entrepreneurship guidance courses, in the construction of campus culture, the development and practice of invisible curriculum resources to promote students' ability to innovate and innovate is still scarce. Existing entrepreneurial projects and practices have low levels of varying degrees. Repeatedly, most students lack the spirit of innovation and entrepreneurship, lack the courage and courage of innovation and entrepreneurship, and lack the consciousness of innovative entrepreneurship. The ultimate result is low student entrepreneurship and lower entrepreneurial success rate.

At present, the sources of innovative and entrepreneurial funds for college students are mainly provided by the government and universities. The sources of venture capital are narrow, and the participation of social and private funds is not high. Entrepreneurship is considered to be the work of colleges. The government and society are not active in the entrepreneurial work of college students. The role of the role is not obvious. The policy design does not really take into account the 
actual demands of entrepreneurs, and its effectiveness is greatly reduced. The weakness of the entrepreneurial support system limits the scale-effectiveness of innovation and entrepreneurship education, and also limits the quality of entrepreneurship.

First, China's colleges' innovation and entrepreneurship education started late compared with foreign developed countries, and development is still in its infancy. There is no benign interactive innovation and entrepreneurship education ecological cultivation system that combines government, universities, society and students. Government, universities, and society the role of the various subsystems such as students has not been fully realized. Second, the evaluation of college students' innovation and entrepreneurship projects has paid too much attention to the preliminary feasibility analysis of entrepreneurial projects, ignoring the late supervision and evaluation of the implementation of the project support projects, and the entrepreneurial practice projects. The tolerance for failure is low.

\section{The Path Choice for the Reform of Innovation and Entrepreneurship Education}

Starting from the concept of promoting students' all-round development, we will further promote quality education, stimulate students' sense of innovation and potential, and play an active role in promoting various educational activities week, such as the Science and Technology Week and the Vocational Education Week. These forms of open education can attract Primary school students are actively involved. In the basic education stage, it is not necessary to be too demanding for students to have standardized and unified answers. It is necessary to work hard to cultivate students' critical thinking and innovative spirit. In addition, it is necessary to break the shackles of the college entrance examination, weaken the screening function of the college entrance examination, promote the classification examination, and form a good educational environment where everyone has the talents and talents.

The teacher's educational philosophy is a key factor in promoting people's growth and development. Teachers' teaching behavior is deeply influenced by their educational philosophy. Therefore, it is necessary to change the existing role predicament of primary and secondary school students in innovation. In addition to the education reform measures introduced by the education department, it is more important to update the concept of teacher education. Primary and secondary education should return to the true nature of education, that is, education is first of all adult education rather than adult education. Basic education is not about "what is the child," but about "how the child wants", and then release the child's nature. And potential. The role of the teacher is the leader, the supporter, and the participant. The teaching method focuses on guidance, support, and encouragement, and should not be excessively excessive intervention and suppression.

In the face of "Qian Xuesen's question", in order to cultivate the lack of innovative talents, colleges must clarify their ideas, take on the heavy responsibility, and take the initiative to respond. First of all, colleges should attach great importance to innovation and entrepreneurship education from the perspective of ideas and concepts, incorporate innovation and entrepreneurship education into the talent cultivation system, integrate into the whole process of education and teaching, gradually cultivate students' creative personality, and promote colleges from "campus entrepreneurship" to "starting campus". Transformation; Secondly, give full play to the radiation and leading role of various innovation and entrepreneurial competitions, and stimulate the awareness of innovation and entrepreneurship of college students through competition; once again, colleges should become the frontiers of innovation culture that cultivates respect for knowledge, advocates creativity and pursues excellence, and improves the entrepreneurial organization within the school. And the management system construction, timely follow-up entrepreneurship guidance services, based on professional, classified guidance, based on school conditions, academic conditions to reshape the innovation and entrepreneurial culture suitable for the school's educational ecology, to achieve "cultural education"; Finally, to create a relaxed entrepreneurial atmosphere Innovative entrepreneurship is not a short-term project that is immediate and immediate, but a complex system project that requires time, technology, market and policy support. Therefore, universities should encourage and guide students to boldly take the pace of entrepreneurship and 
maintain the success of students' innovation and entrepreneurship. Tolerance.

\section{Conclusion}

The intention and ability of students to innovate and start a business depends largely on the teacher's ability to teach and guide entrepreneurship education. The ability of teachers' entrepreneurial education comes from continuous entrepreneurship training and practice. In order to cultivate innovative and entrepreneurial talents in colleges, we must first start from the construction of teachers' innovative and entrepreneurial capabilities. In the construction of teachers, we must implement the "introduction" strategy, break through the existing personnel management system, break the barriers, and introduce outstanding talents from industry enterprises as practical mentor for entrepreneurship courses. In the mode of integration of production and education, school-enterprise cooperation, the practice of innovation and entrepreneurship education is highlighted, and the teacher entrepreneurship guidance training program is implemented to support more teachers to "go global" and encourage qualified in-service teachers to go deep into the company to promote their teachers' knowledge. And the renewal of ideas, strengthen the construction of teachers' entrepreneurial education and teaching ability, and promote the improvement of students' entrepreneurial ability with the development of teachers' entrepreneurial teaching ability.

\section{Acknowledgements}

Fund: Key Research Base of Philosophy and Social Science of Shaanxi Provincial Department of Education. Research on Innovation and Entrepreneurship Education Model of Private Colleges in Shaanxi Province 17JZ062.

\section{References}

[1] Ma Xiaohui. Ecological Civilization of Entrepreneurship Education [J]. Education and Occupation, 2014, (7).

[2] Hong Dayong. Creating an upgraded version of innovation and entrepreneurship education [J]. China Higher Education, 2016, (2).

[3] Yan Jianhua. Constructing “Innovation-based Entrepreneurship” Education [J]. China Higher Education, 2016, (12).

[4] Ma Luting. Higher education needs to have an overall structure for supporting national technological innovation [J]. Higher Education Research, 2016, (1). 